\title{
anatomy
}

Original Article

www.anatomy.org.tr

\section{Graphene oxide has a neuroprotective effect against glutamate-induced excitoxicity on B35 neuroblastoma cell line*}

\author{
Buse Kayhan ${ }^{1}$, Şeyma Taşdemir ${ }^{2}$, Pelin Çoruk İlhan ${ }^{1}$, Cansu Görgün ${ }^{3}$, \\ Aylin Şendemir Ürkmez ${ }^{1,2,3}$, Gülgün Şengül ${ }^{1,4}$ \\ ${ }^{I}$ Department of Neuroscience, Institute of Health Sciences, Ege University, Izmir, Turkey \\ ${ }^{2}$ Department of Bioengineering, Faculty of Engineering, Ege University, Izmir, Turkey \\ ${ }^{3}$ Department of Biomedical Technologies, Graduate School of Natural and Applied Sciences, Ege University, Izmir, Turkey \\ ${ }^{4}$ Department of Anatomy, Faculty of Medicine, Ege University, Izmir, Turkey
}

\begin{abstract}
Objectives: Graphene is a quasi-two-dimensional material with unique electrical and chemical properties. In terms of biomedical applications of graphene, nervous system would be an ideal breakthrough model because neural cells are electroactive. Extreme glutamate concentrations cause excitotoxicity. In this study, we aimed to investigate if graphene can increase the resistance to glutamate stress in B35 rat neuroblastoma cells as a cultured cell model for central nervous system neurons.

Methods: B35 neuroblastoma cells were grown in DMEM-F12 growth medium containing 10\% fetal bovine serum. Graphene oxide (GO) powder was coated onto glass slides with chitosan as a thin film. B35 cells were cultured on GO films. Cells cultivated on glass slides were used as controls. After $24 \mathrm{~h}$ of cell culture, L-glutamine induced excitotoxicity was imposed on B35 cells. After $24 \mathrm{~h}$ of glutamate-induced stress, cell morphology was examined by scanning electron microscopy. Cell viability was measured with MTT assay.

Results: The effects of glutamate stress on cell viability were visible as early as $1 \mathrm{~h}$. The cell viability on GO films was higher than that on glass slides, and cells recovered from stress within $6 \mathrm{~h}$ on GO surfaces. After $24 \mathrm{~h}$, viability on glass surfaces was $54 \%$ lower than that on GO surfaces; these findings were supported with cell morphology observations.

Conclusion: The results of this study showed that GO has a protective role in reducing glutamate-induced excitotoxicity in B35 cell culture, indicating a potential use of GO for treatment of excitotoxicity induced neurodegenerative diseases.
\end{abstract}

Keywords: B35 cell line; excitotoxicity; glutamate stress; graphene oxide

Anatomy 2015;9(3):156-167 @2015 Turkish Society of Anatomy and Clinical Anatomy (TSACA)

\section{Introduction}

Glutamate is one of the main excitatory neurotransmitters in the central nervous system (CNS), involved in neural transmission, development, differentiation and plasticity. It plays a vital role in neural pathways for cognition, memory and learning, and synapse induction and elimination during development, cell migration, differentiation and death. Glutamate is continuously released from neurons and uptaken from extracellular fluid. There are no enzymes in the extracellular environment that can degrade glutamate. Most neurons and glial cells have glutamate receptors in their plasma membranes.

*This study was presented at the XXIV International Symposium on Morphological Sciences (ISMS), 2-6 September 2015, Istanbul, Turkey 
Glutamate concentration regulates the extent of receptor stimulation. Extracellular glutamate concentration should be kept low because excessive stimulation of glutamate receptors may cause excitotoxicity. ${ }^{[1,2]}$ Excitotoxicity is linked with many neurodegenerative conditions such as Huntington's disease, Alzheimer's disease, amyotrophic lateral sclerosis, Parkinson's, stroke and traumatic brain injury. ${ }^{[3]}$

To investigate the effects of glutamate stress on an in vitro model of CNS, we used B35 cell line, which has been shown useful in the molecular analysis of endocytosis and signaling pathways, in particular, those that guide axonal outgrowth and cell motility. ${ }^{[4]}$ B35 neuroblastoma cells can be induced to differentiate reversibly, extending long neurites even in low serum conditions, so they are particularly useful for CNS neuronal differentiation and neurite outgrowth studies. They provide substantial advantages over primary CNS neurons in cell biology and biochemistry experiments, because of their ease of culture, efficiency of transfection and ability to establish stable cell lines. ${ }^{[5]}$

Glutamate may be directly toxic to cultured neuronal cells via two different processes that result in production of free radicals. The classical pathway, excitotoxicity, is through the activation of N-methyl-D-aspartate (NMDA) and non-NMDA glutamatergic receptors, and subsequent calcium influx into the cell. ${ }^{[6]}$ The second pathway is oxidative glutamate toxicity pathway, which is a transporter-mediated type of cell death. ${ }^{[7]}$ This pathway requires cellular expression of the cystine /glutamate antiporter system shown in primary neuronal cultures, ${ }^{[7-11]}$ neuronal cell lines ${ }^{[7,11-14]}$ and tissue slices. ${ }^{[15]}$ The competition of glutamate with cystine for the cystine/glutamate antiporter induces an imbalance in the homeostasis of cystine, the precursor of glutathione (GSH). Therefore, the inhibition of cystine uptake by constant and high exposure to glutamate causes an inability to maintain intracellular GSH levels, leading to a reduced protection against oxidative injury and cell death. The accumulation of excess free radicals seems to be responsible for excitotoxicity. This second pathway can be blocked by antioxidants. ${ }^{[11,14]}$

In CNS, glutamate transporters play the main role in regulating the physiological clearance of neurotransmitters from the synaptic cleft. ${ }^{[16]}$ Under specific circumstances, glutamate transporters may also play a neuroprotective role. ${ }^{[17-20]}$ High and prolonged exposure to glutamate is a critical event for the pathogenesis of numerous neurological disorders, ${ }^{[21,22]}$ either acute, such as stroke $^{[23]}$ and epilepsy, ${ }^{[24]}$ or chronic, such as Alzheimer's disease ${ }^{[25]}$ Parkinson's disease, ${ }^{[26]}$ and amyotrophic lateral sclerosis. $^{[27]}$

Neural tissue repair and regeneration research has been at the forefront lately, due to the adverse impact of neurological diseases on patient's life quality. In recent years, the emergence of nanotechnology provided a promising strategy for treatment of neurodegenerative diseases. ${ }^{[28,29]}$ Researchers implanted nanometer-scale scaffolds to support and promote neurite and axonal growth using tissue-engineering approaches. ${ }^{[28]}$ In experimental in vitro studies to test novel treatment strategies, the use of $3 \mathrm{D}$ culture constructs can modulate cell behavior and tissue development, and mimic extracellular matrix (ECM) with unique biomaterials to support realistic in vitro tissue and disease models. Biomedical nanotechnology, electrospinning technique and tissue engineering methods give us exciting insights to the design of a 3D construct with good electrical, mechanical and biological properties as well as compliance match closely resembling the native ECM. ${ }^{[30]}$

Graphene is one of the most attractive nano-structured materials consisting of a monolayer of sp2-bonded carbon atoms. This quasi-two-dimensional (2D) material has high transmittance and excellent conductivity. Graphene and graphene oxide (GO) sheets are biocompatible platforms that have the potential to mediate stem cell lineage specification for tissue regeneration. As neuronal cells are electro-active and their function is based on electrical activity, graphene is suitable as a substrate for neural cells. ${ }^{[31]}$ Graphene and its derivatives (graphene oxide or reduced graphene oxide) are used as scaffolds to support cellular attachment, proliferation and differentiation. ${ }^{[32-34]}$ To grow or communicate with neighboring cells, neurons secrete substances, many of which are adsorbed on graphene surfaces, and subsequently affect cell proliferation and differentiation. ${ }^{[35]}$ Due to its unique electrical properties, graphene and GO are considered as potential treatments for regulating neural cell behavior in degenerative CNS conditions. ${ }^{[31]}$

GO can be easily dispersed in many solvents and especially well in water, which does not lessen biocompatibility, and also facilitate any subsequent processing. ${ }^{[3]}$ We used GO films prepared on chitosan (CS) coated glass surfaces as culture substrate. CS is produced through deacetylation of chitin, one of the most commonly found natural polymers on earth. ${ }^{[37]}$ It is a biocompatible and biodegradable hydrophilic biopolymer and has multiple functional groups. CS is protonated in acid media, which favor the interaction between polymer 
chains and GO sheets, and allow dispersion of GO as a thin film onto CS coating. ${ }^{[38]}$

In this study, we used B35 neuroblastoma cells as a suitable model for CNS neurons and investigated if GO may have a neuroprotective effect under glutamate stress, and therefore if it may be useful in the treatment of neurodegenerative diseases.

\section{Materials and Methods Preparation of graphene oxide films}

Graphene oxide was purchased from Graphene Chemical Industries Co., 2\% (w/v) chitosan (Sigma C3646; Sigma-Aldrich, Taufkirchen, Germany) was prepared by dissolving in $0.2 \mathrm{M}$ acetic acid for a day on magnetic stirrer. $10 \mathrm{mg} / \mathrm{mL}$ graphene oxide suspension was prepared in distilled water. After a homogenous dispersion was obtained, chitosan solution was dropped onto glass slides. Immediately after chitosan was spread on glass, graphene oxide suspension was dripped slowly on chitosan films. The resulting coatings were allowed to dry overnight under fume hood. Each coverslip was sterilized by exposing to UV light for 2 hours (Figure 1).

\section{Cell culture}

B35 rat neuroblastoma cells were obtained from Ege University Bioengineering Department, Animal Cell Culture and Tissue Engineering Laboratories. B35 cells were cultured in Dulbecco's Modified Eagle Medium F12 (DMEM-F12) (F4815; BioChrom AG, Berlin, Germany) growth medium supplemented with $1 \% \mathrm{~L}$ glutamine (K0282; BioChrom AG, Berlin, Germany), $0.1 \%$ gentamycin (BioChrom AG, A2710) and 10\% fetal bovine serum (FBS) (S0115; BioChrom AG, Berlin, Germany) at $37{ }^{\circ} \mathrm{C}$ in a $5 \% \mathrm{CO}_{2}$ incubator. Cell media were changed every $48 \mathrm{~h}$. Cells were seeded onto GO films and glass slides at a concentration of $105 \mathrm{cells} / \mathrm{cm}^{2}$ and cultured for $24 \mathrm{~h}$ before L-glutamine exposure. ${ }^{[39]}$

\section{Glutamate excitotoxicity}

After $24 \mathrm{~h}$ of cell culture, B35 cells on both surfaces were treated with $150 \mathrm{mM} \mathrm{L}$-glutamine to induce excitotoxicity. Different groups of B35 cells were exposed to Lglutamine for durations of 1, 3, 6 and $24 \mathrm{~h}$. After L-glutamine exposure for given durations, culture media on the cells were replaced by fresh growth media, and the culture was continued until total of $24 \mathrm{~h}$. Each experimental and control treatment was applied on five replicates $(\mathrm{n}=5)$.

\section{Cell viability assay}

The colorimetric 3-(4,5-dimethylthiazol-2-yl)-2, 5diphenyltetrazolium bromide (MTT) (Sigma M5655; Sigma-Aldrich, Taufkirchen, Germany) test assess cellular metabolic activity on the basis of the ability of mitochondrial succinate-tetrazolium reductase to convert the yellow tetrazole dye (MTT) to a purple-colored formazan in viable cells. The metabolic activity of the cells is proportional to the color density produced. Briefly, following B35 cell incubation for $24 \mathrm{~h}$, the culture medium was aspirated and serum-free DMEM-F12 media containing 10\% v/v MTT stock solution $(5 \mathrm{mg} / \mathrm{mL}$ MTT dissolved in PBS) were added to each sample and they were incubated at $37{ }^{\circ} \mathrm{C}$ and $5 \% \mathrm{CO}_{2}$ for $3 \mathrm{~h}$. The supernatant was removed, and the formazan crystals were dissolved in dimethylsulfoxide (DMSO, Sigma 41640; Sigma-Aldrich, Taufkirchen, Germany). Absorbance was recorded at 570 $\mathrm{nm}$ and $690 \mathrm{~nm}$ using a microplate reader VersaMax; Molecular Devices, Sunnyvale, CA, USA). ${ }^{[40]}$

\section{Evaluation of cell morphology}

To evaluate possible changes in B35 cell morphology induced by L-glutamine, light and scanning electron microscopy (SEM) images were examined. Phase contrast images were captured using an inverted light microscope (Olympus CK 40; Olympus, Tokyo, Japan) after 1, 3,6 and $24 \mathrm{~h}$.

To prepare the samples for SEM, they were washed with PBS for $30 \mathrm{~s}$ and fixed with $5 \%(\mathrm{v} / \mathrm{v})$ glutaraldehyde (25\%, Merck, 8.20603.1000; Merck, Darmstadt, Germany) in $0.1 \mathrm{M}$ sodium cacodylate (Sigma CO250; Sigma-Aldrich, Taufkirchen, Germany) for $30 \mathrm{~min}$ at +4 ${ }^{\circ} \mathrm{C}$. Glutaraldehyde was aspirated and $7 \%$ sucrose in 0.1 $\mathrm{M}$ sodium cacodylate was applied for $15 \mathrm{~min}$. at $+4{ }^{\circ} \mathrm{C}$ twice. The samples were post fixed with $2 \%$ osmium tetroxide in $0.1 \mathrm{M}$ sodium cacodylate for $30 \mathrm{~min}$. on ice. They were washed three times with distilled water for 5 min., dehydrated in ethanol series $(35 \%, 50 \%, 70 \%, 85 \%$, $95 \%$ and $100 \%$ ) and rinsed with hexamethyldisilazane (HMDS) for $5 \mathrm{~min}$. and air dried at room temperature for $30 \mathrm{~min}$. After being completely dried, the samples were mounted on aluminum pins with double-sided carbon tape and sputter coated with gold, and observed by SEM (JEOL JSM-6060; Jeol, Tokyo, Japan).

\section{Actin cytoskeleton staining}

Cells on GO and glass surfaces were fixed with a $4 \%$ paraformaldehyde solution (USB 19943; USB, Cleveland, OH, USA) for $15 \mathrm{~min}$. Each sample was washed 2 times with $\mathrm{PBS}$ without $\mathrm{Ca}+2$ and $\mathrm{Mg}+2$. 
Then, NH4 Cl (Sigma A9434; Sigma-Aldrich, Taufkirchen, Germany) solution was added for $7 \mathrm{~min}$. to quench the fixative. Cells were permeabilized with $0.2 \%$ PBS-Triton X-100 (A1388; AppliChem, Darmstadt, Germany) for $15 \mathrm{~min}$, and stained with 1:1000 DAPI, 1:100 Alexa Fluor 488 Phalloidin (Invitrogen A12379; Thermo Fisher Scientific, Waltham, MA, USA) for 40 min. Access water was removed, and the coverslip was inverted on a slide on $10 \mu \mathrm{L}$ Mowiol 4-88 (Calbiochem, Merck 475904; Merck Millipore, Darmstadt, Germany) mounting medium. They were kept overnight at $4{ }^{\circ} \mathrm{C}$ to dry, and imaged using a fluorescence microscope (AXI0; Zeiss, Oberkochen, Germany).

\section{Statistical analysis}

For cell viability analysis, data were expressed as mean \pm standard error (SE) based on five replicate observations from two independent experiments. Statistical significance was determined by one-way analysis of variance (ANOVA) followed by Dunnett's multiple comparison test. A value of $\mathrm{p}<0.05$ was considered statistically significant. All analyses were conducted using the Prism software package (GraphPad Software, La Jolla, CA, USA).

\section{Results}

Toxic effects of L-glutamine exposure on $\mathrm{B} 35$ cell viability was visible as early as $1 \mathrm{~h}$. Cells that were exposed to L-glutamine showed decreased number of neurites, and visible accumulation compared to control group (Figures 2a and $\mathbf{b}$ ).
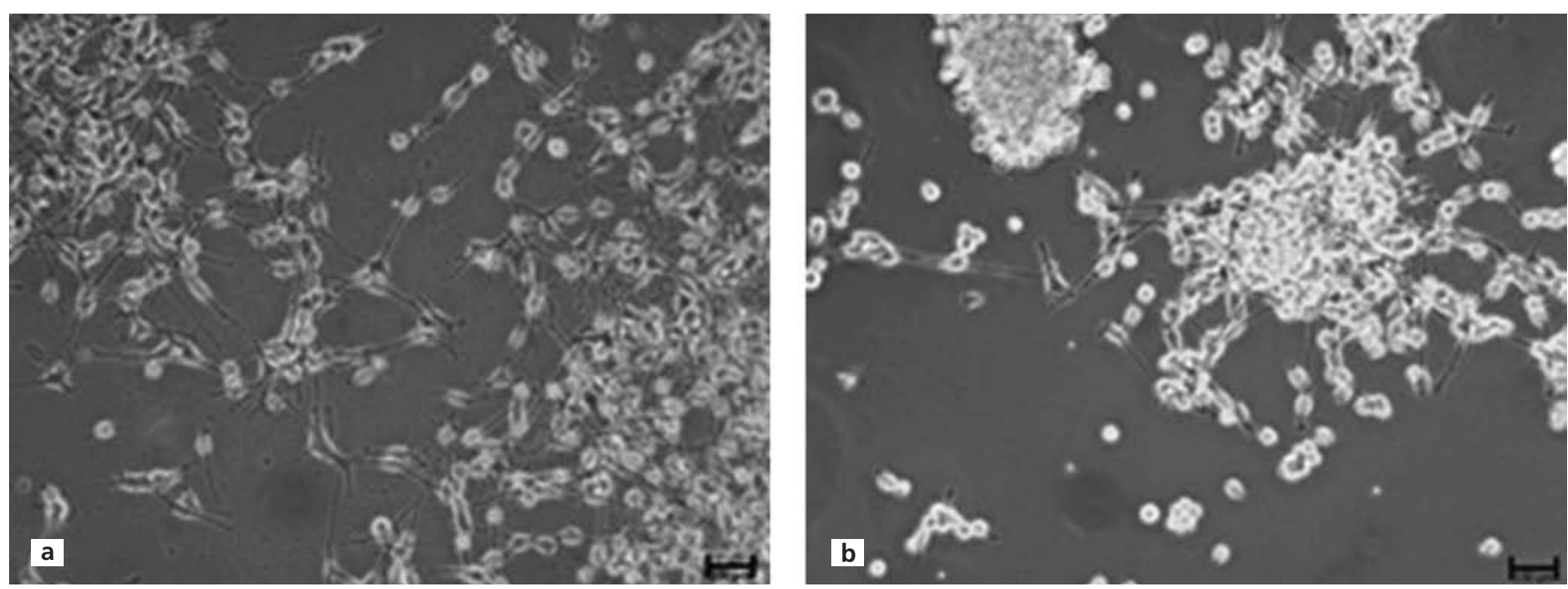

Figure 2. B35 neuroblastoma cells under light microscopy before and after addition of 150 mM L-glutamine. (a) Control B35 cells, (b) B35 cells treated with L-glutamine for $1 \mathrm{~h}$. Scale bar $=100 \mu \mathrm{m}$. 
a

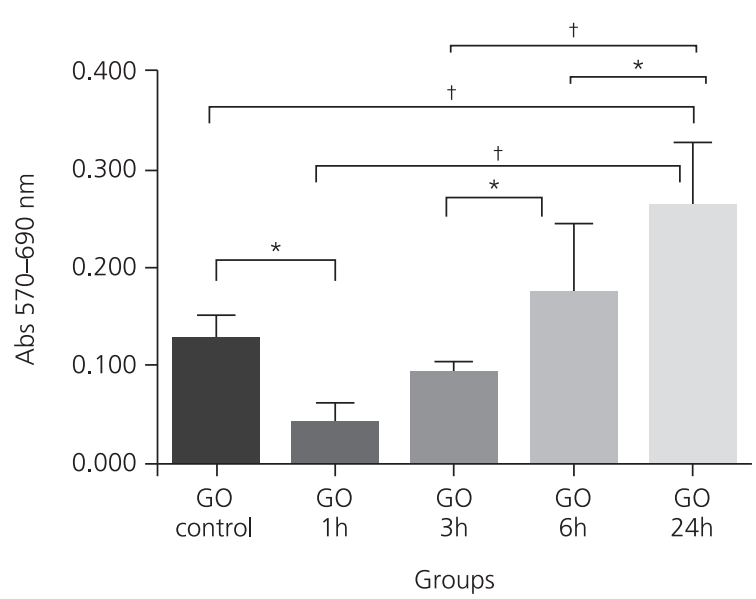

b

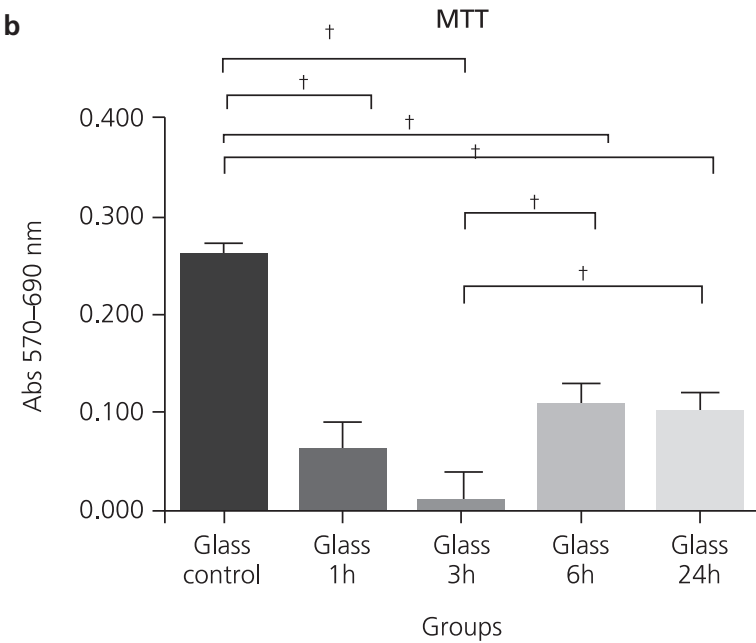

Figure 3. Cell viability after glutamate stress $(\mathbf{a}, \mathbf{b}) .{ }^{*} p<0.02,{ }^{\dagger} p<0.0002$.

Fluorescence microscopy images showed that the cell number and viability started to be affected after $1 \mathrm{~h} \mathrm{~L}$-glutamine exposure, (Figure 4b). After $6 \mathrm{~h} \mathrm{~L}$-glutamine exposure, B35 cells were adapted to glutamate stress on GO surfaces (Figure 4d). This observation is parallel with MTT assay results. We could not take clear fluorescent images on GO films, because the neurites are overlapped and chitosan has auto-fluorescence (Figure 5).

SEM images show the decreased cell number after $1 \mathrm{~h}$ L-glutamine exposure on both surfaces (Figures $\mathbf{6 b}$ and $7 \mathbf{b})$. Higher cell numbers are visible on GO surface compared to glass slides after $24 \mathrm{~h} \mathrm{~L}$ - glutamine exposure (Figures 6e and 7e). The MTT assay supported this observation.

The effects of glutamate stress on cell viability were visible as early as 1 hour on both surfaces. The cell viability of B35 cells on GO sheets was higher than on glass slides, and cells recovered from the stress within 6 hours on GO surfaces while viability on glass surfaces was $54 \%$ lower than that on GO surfaces after 24 hours. Cell morphology and toxicity measurements also supported these observations.

\section{Discussion}

In this study, we investigated whether GO may have a neuroprotective effect on B35 cell culture, a model for CNS neurons, under glutamate stress and therefore, if it may be useful in the treatment of neurodegenerative diseases linked to glutamate stress. We have demonstrated that glutamate is toxic to B35 cells above the concentration of $100 \mathrm{mM}$. The culture on GO films increased the resistance of B35 cells to glutamate stress, and helped fast recovery as shown in our results with MTT (Figure 3), fluorescence microscopy (Figures 4 and 5) and SEM microscopy (Figures 6 and 7).

Neuronal cells are electro-active and their function is based on electrical activities. Therefore graphene, being electrically conductive, has been shown suitable for neural cell adhesion. ${ }^{[3]} \mathrm{Li}$ et al. ${ }^{[41]}$ also showed that graphene exhibits excellent biocompatibility during the development and maturation in a mouse hippocampal culture model. This study demonstrated that viability of the neural cells and average of neurite lengths on graphene substrates were significantly enhanced compared to the conventional polystyrene tissue culture substrates, indicating that graphene is a neuron-favorable material.

Due to their unique electrical properties, graphene and graphene oxide can also be considered in potential treatment strategies for regulating neural cell behavior in CNS degeneration. Park et al..$^{[42]}$ showed that graphene induced differentiation of human neural stem cells (hNSCs) to neurons more effectively compared to glass substrates. Weaver et al. ${ }^{[4]}$ also explored the potential of a GO/PEDOT (poly 3,4-ethylenedioxythiophene) nanocomposite films for NSCs differentiation in vitro and showed that they GO composites promoted neuronal differentiation while only PEDOT surfaces lead more toward oligodendrocyte differentiation. On the contrary, Shah et al. ${ }^{[4]}$ used nanofibrous scaffolds with graphene to guide NSC differentiation to oligodendrocytes without any differentiating agent. They observed that coating with a higher concentration of GO promoted differentiation toward mature oligodendrocytes. 

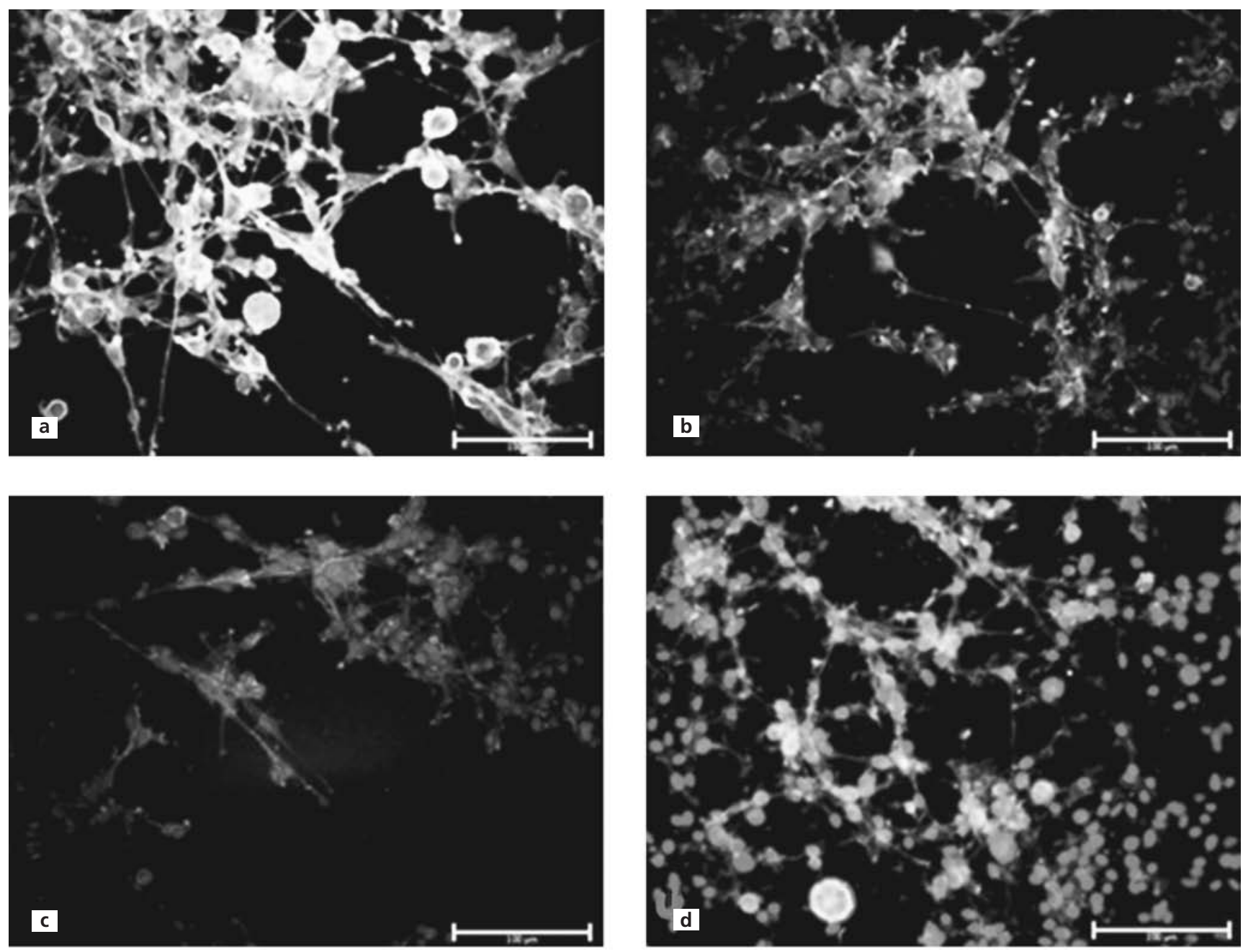

Figure 4. Fluorescence microscope images (40x) on glass slides. Green (Alexa Fluor 488 Phalloidin staining) shows actin, blue (DAPI staining) shows nuclei. (a) No stress condition, (b) 1h, (c) 3h, (d) 6h, and (e) $24 \mathrm{~h} \mathrm{L-glutamine} \mathrm{exposure.} \mathrm{Scale} \mathrm{bar}=100 \mu \mathrm{m}$.

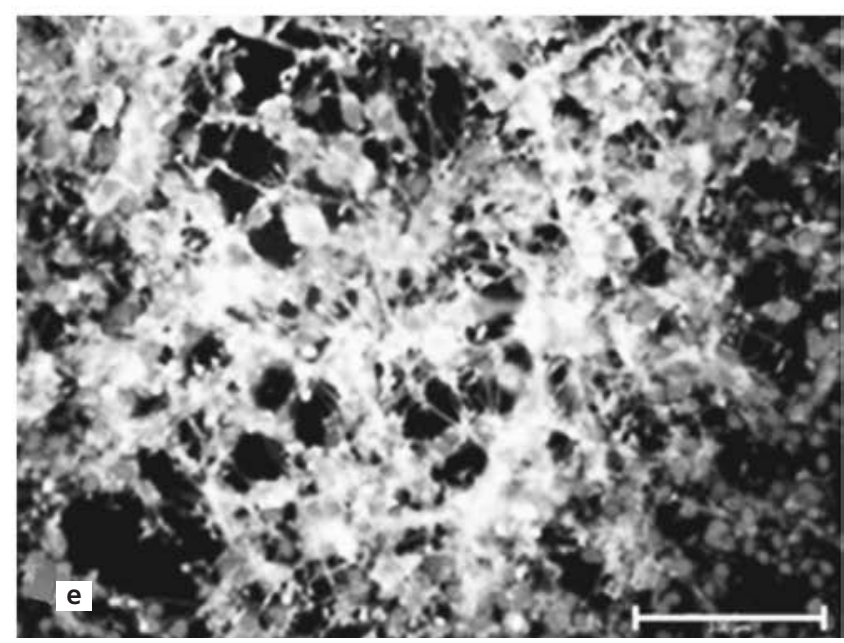

Wang et $\mathrm{al}^{[45]}$ demonstrated that fluorinated graphene enhanced cell adhesion and proliferation of mesenchymal stem cells (MSCs), induced cell polarization and promoted differentiation to neuronal lineage.
Lee et al. ${ }^{[46]}$ showed that MSCs exhibited different morphologies on graphene, graphene oxide and PMDS (polydimethylsiloxane) substrates. On PMDS, cells appeared round and lacked filopodia extensions; but on 

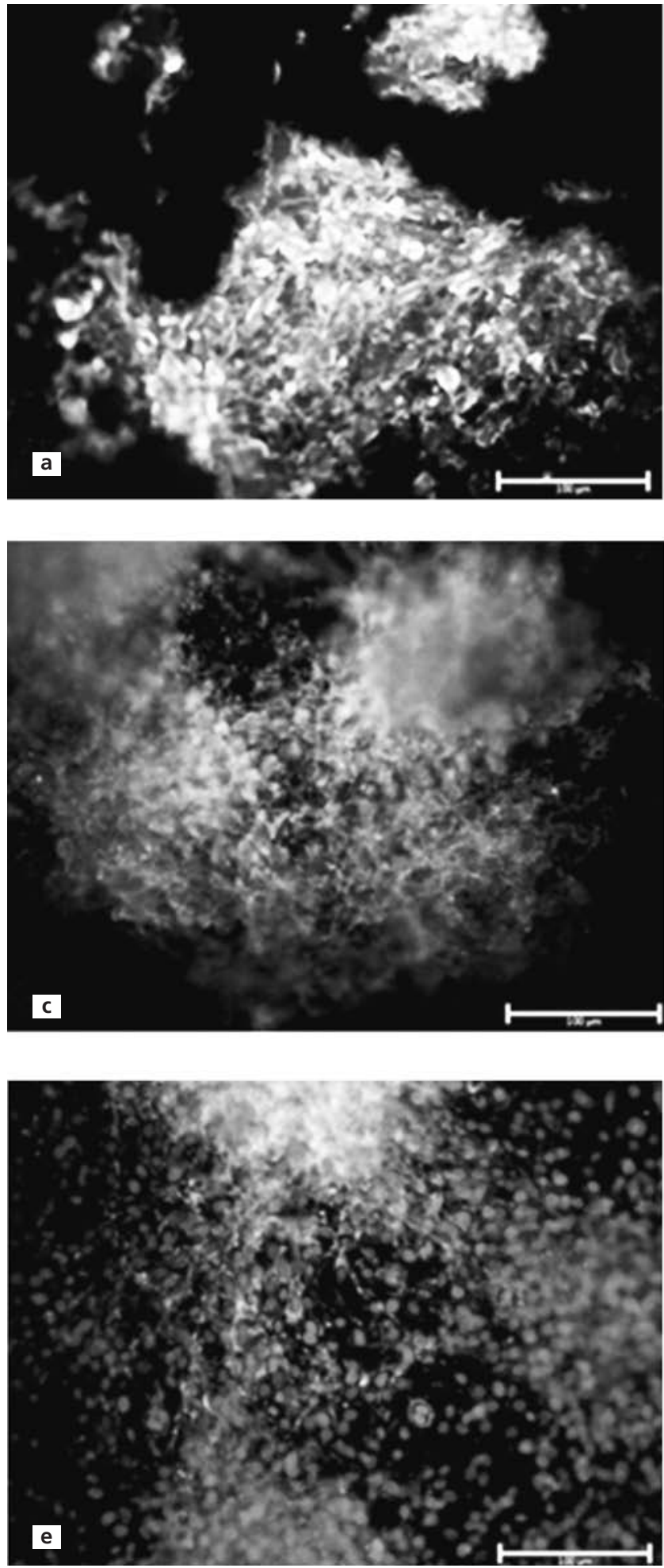

graphene films, they had spindle shaped morphology, whereas on GO films, they were widespread and larger. These studies suggest that graphene can be used as a nanostructured scaffold for controlling the differentia-
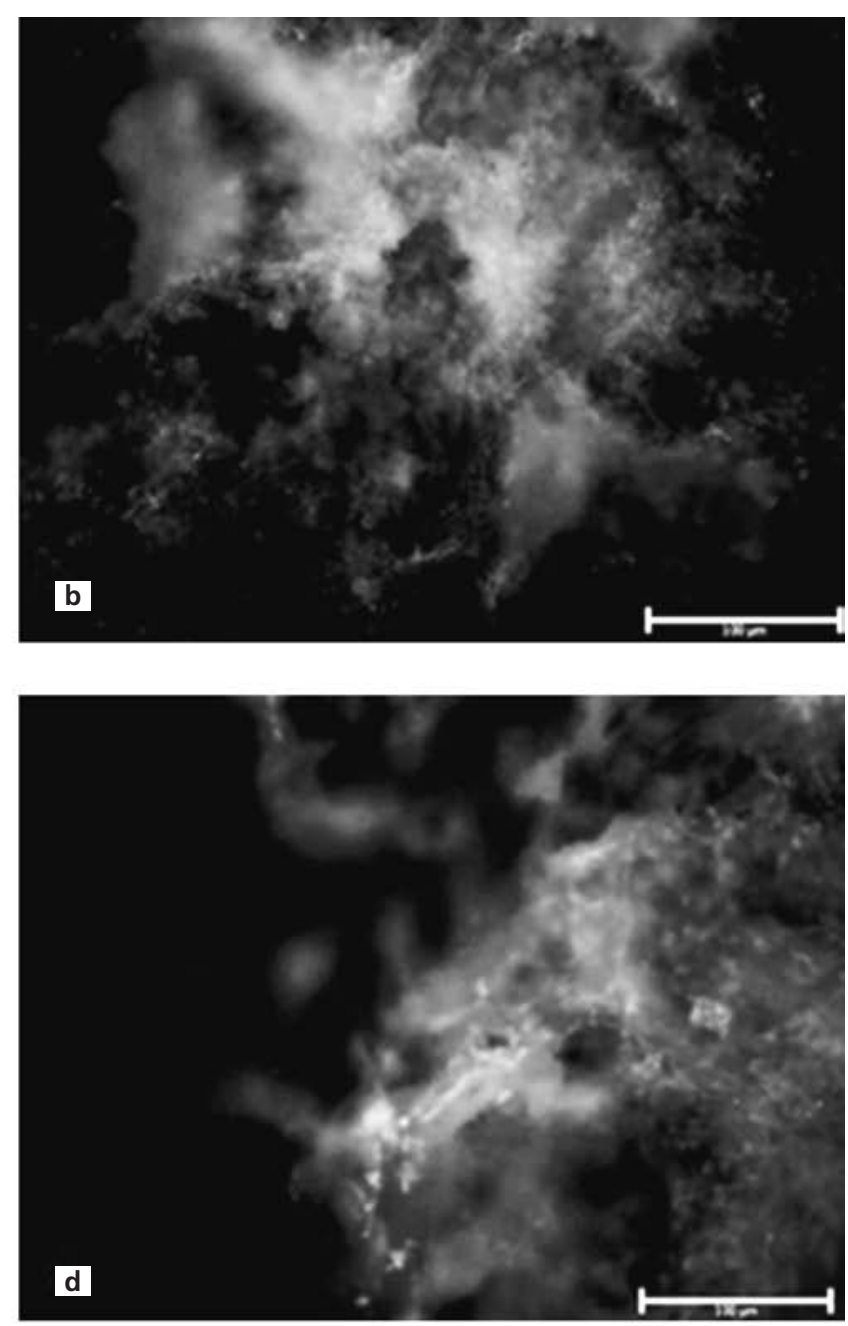

Figure 5. Fluorescence microscope images (40x) on GO films. Green (Alexa Fluor 488 Phalloidin staining) shows actin, blue (DAPI staining) shows nuclei. (a) No stress condition, (b) 1h, (c) 3h, (d) 6h, and (e) 24h L-glutamine exposure. Scale bar $=100 \mu \mathrm{m}$.

tion of stem cells in a concentration dependent manner for neural regenerative medicine.

In this study, we used chitosan as a vehicle to hold GO flakes as a film on the surface. Chitosan, itself, is a 

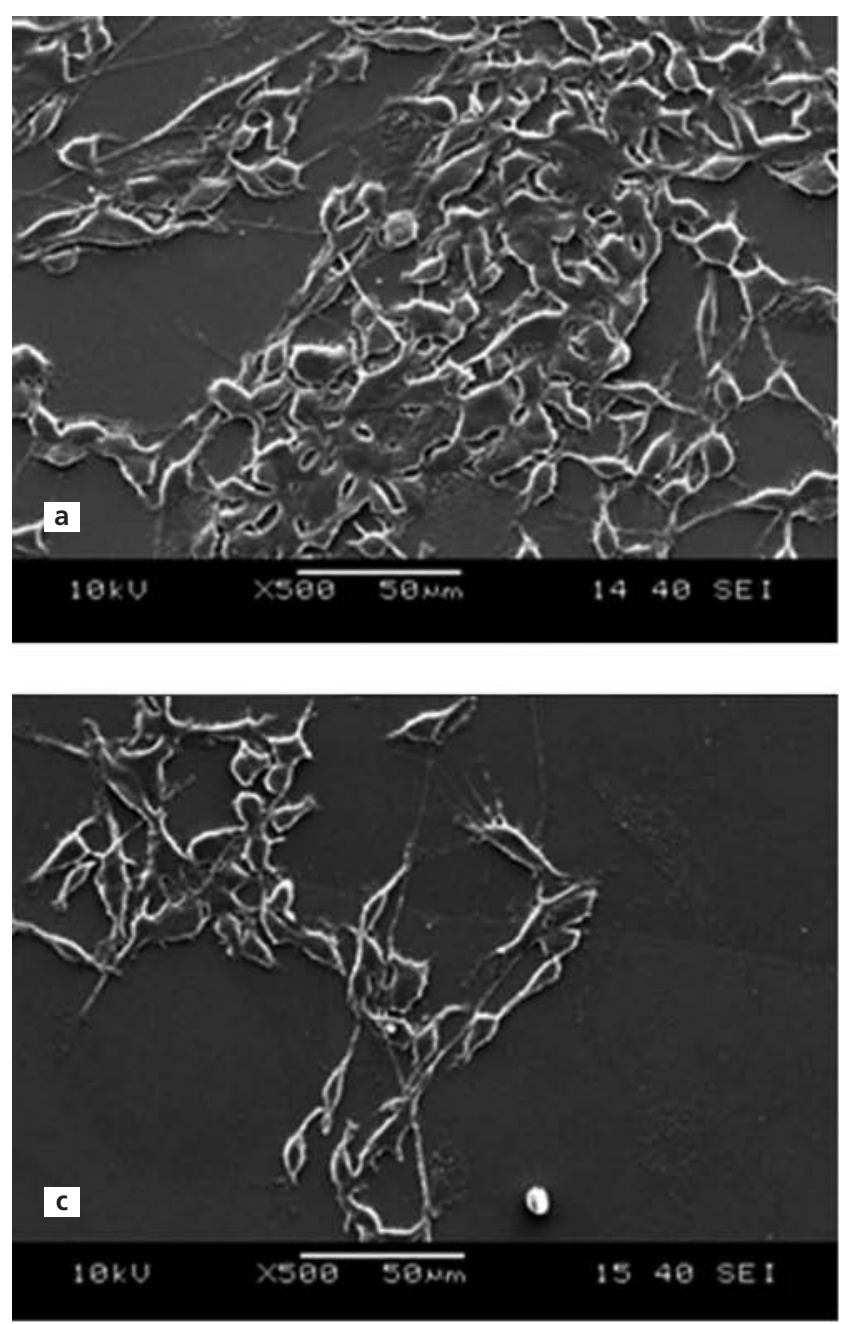

Figure 6. Scanning electron microscope images on glass slides. (a) No stress condition, (b) $1 \mathrm{~h}$, (c) 3h, (d) 6h, and (e) 24h L-glutamine exposure.
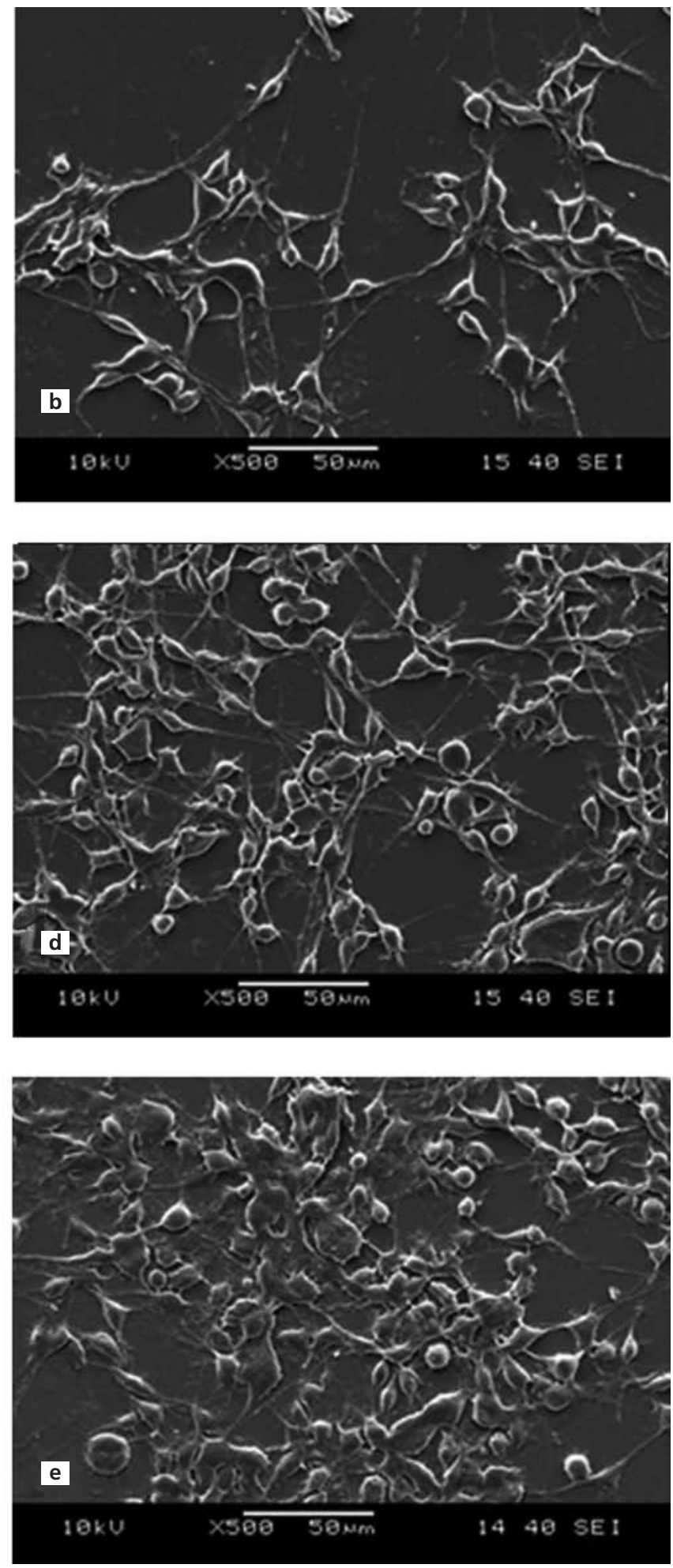

attachment, proliferation and growth. Zuo et al.$^{[48]}$ used three different films, chitosan, GO-chitosan and $\mathrm{GO} /$ chitosan mix to investigate the potential application of $\mathrm{C} 3 \mathrm{H} 10 \mathrm{~T} 1 / 2$ cells in growth of articular carti- biocompatible material. Depan et al. ${ }^{[4]}$ used chitosangraphene network structured scaffolds to cultivate MC3T3-E1 mouse pre-osteoblast cell line, and also observed that chitosan-graphene film facilitated cell 

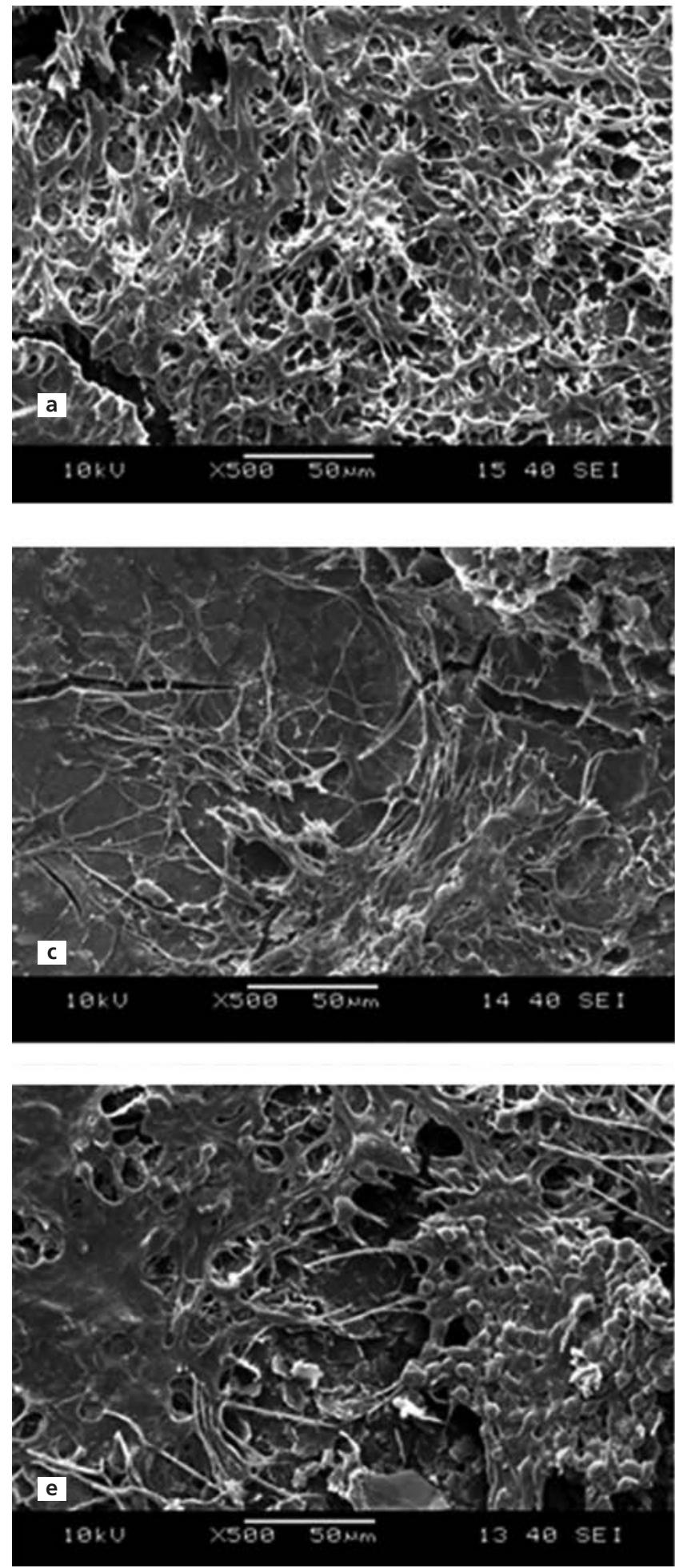

lage. They observed that GO-chitosan film had good biocompatibility, biodegradability, good solubility in aqueous medium and was suitable for cell proliferation. Pan et al. ${ }^{[49]}$ also showed green production of nanocom-
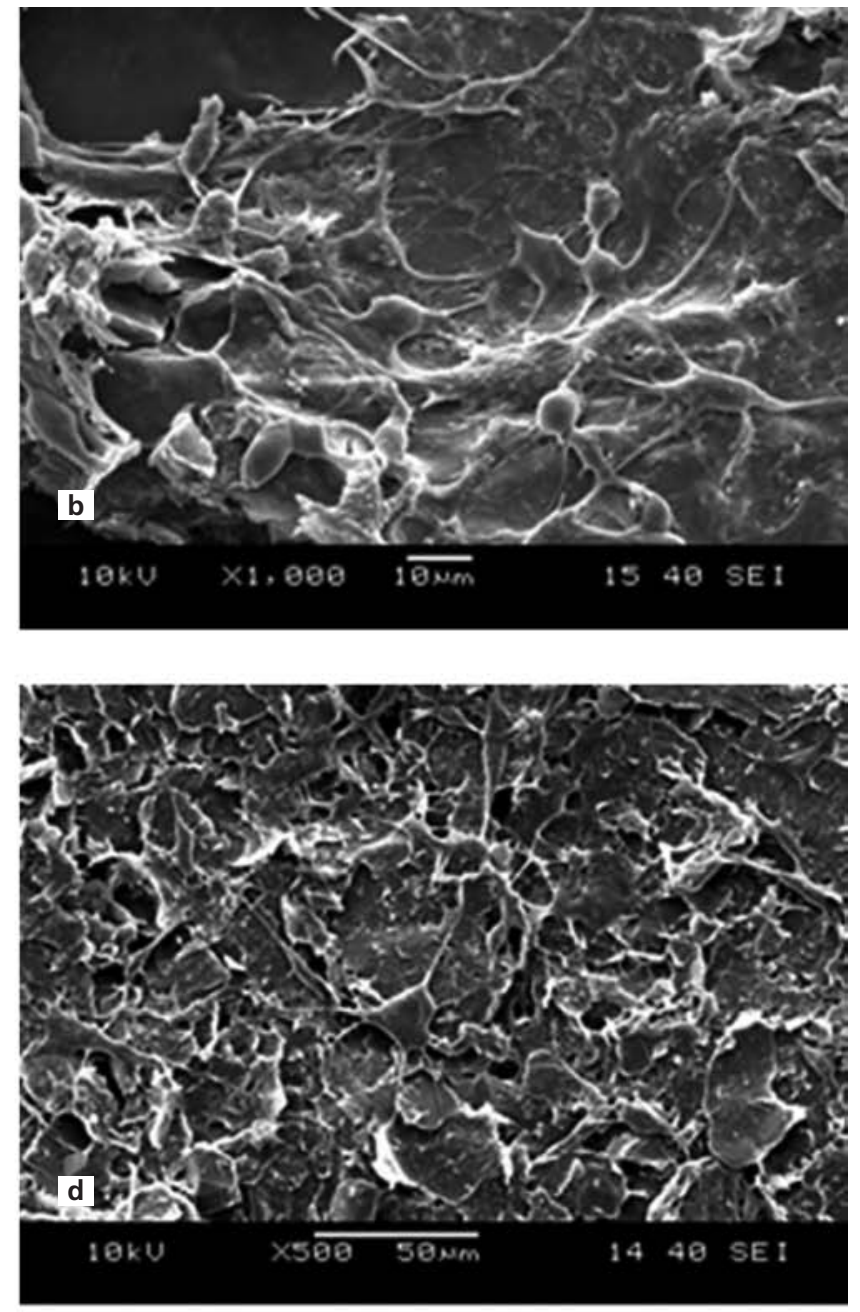

Figure 7. Scanning electron microscope images on GO films. (a) No stress condition, (b) 1h, (c) 3h, (d) 6h, and (e) 24h L-glutamine exposure.

posite $\mathrm{GO} /$ chitosan films by dissolving chitosan in aqueous acetic acid solution and adding GO suspension into the chitosan solution. To the authors' knowledge, there are no other studies in the literature investigating 
the effects of chitosan assisted GO films on neural cell behavior.

Rapid removal of glutamate from the extracellular space is required for the survival and normal function of neurons; excessive concentrations cause excitotoxicity. ${ }^{[50]}$ Greene and Tischler ${ }^{[51]}$ studied with PC12 cells with induced glutamate stress. They showed that toxic effects of glutamate on PC12 occur in a dose and time dependent manner. Toxic concentration of glutamate varies between 0.01 and 10 $\mathrm{mM},{ }^{[52-57]}$ while time varies from $30 \mathrm{~min}$ to $3,12,24$, and 48 $\mathrm{h}$ of incubation. There are also studies reporting that excitotoxic cell death in PC12 cells can be effected by apoptosis and necrosis. ${ }^{[58-60]}$ We have demonstrated that glutamate is toxic to B35 cells above the concentration of $100 \mathrm{mM}$ and chose the concentration of $150 \mathrm{mM}$.

Our results indicate that GO film substrates support CNS cell attachment and proliferation, as well as increase their resistance toward glutamate-induced excitotoxicity. It is possible that GO, with its electrical conductivity, is providing biomimetic cues to the cells, and implementing a suitable niche for cell-cell and cell-extracellular matrix interactions for improved cellular homeostasis to resist glutamate mediated excitotoxicity. This observation suggests that GO based biomaterials may find future applications in neural interfacing and in novel therapeutic approaches for neurodegenerative disorders. Using aqueous chitosan solutions to assist GO film production was successfully achieved, and showed no detrimental effect on cellular viability; but we were not able to take clear fluorescent images because chitosan has auto-fluorescence (Figure 5). Therefore, another method for GO film production might be more suitable for easier observation of cell behavior.

\section{Conclusion}

The results of this study showed that culture of CNS model cell line (B35) on GO films increases the resistance of the cells against glutamate stress. This attribute of the material suggests that there may be a potential use of GO as a therapeutic biomaterial for neurodegenerative diseases that are linked to glutamate-induced excitotoxicity.

\section{Acknowledgements}

This study was supported by TUBITAK (The Scientific and Technological Research Council of Turkey), Grant number: $115 \mathrm{~S} 066$.

\section{References}

1. Zhou Y, Danbolt NC. Glutamate as a neurotransmitter in the healthy brain. J Neural Transm 2014;121:799-817.
2. Danbolt NC. Glutamate uptake. Prog Neurobiol 2001;65:1-105.

3. Kritis AA, Stamoula EG, Paniskaki KA, Vavilis TD. Researching glutamate- induced cytotoxicity in different cell lines: a comparative/collective analysis/study. Front Cell Neurosci 2015;17:9-91.

4. Otey CA, Boukhelifa M and Maness P. B35 neuroblastoma cells: an easily transfected, cultured cell model of central nervous system neurons. Methods Cell Biol 2003;71:287-304.

5. Hosseini M, Khabbaz H, Dezfoli AS, Ganjali MR, Dadmehr M. Selective recognition of Glutamate based on fluorescence enhancement of graphene quantum dot. Spectrochim Acta A Mol Biomol Spectrosc 2014;136PC:1962-6.

6. Michaels RL, Rothman SM. Glutamate neurotoxicity in vitro: antagonist pharmacology and intracellular calcium concentrations. J Neurosci 1990;10:283-92.

7. Murphy TH, Miyamoto M, Sastre A, Schnaar RL, Coyle, JT. Glutamate toxicity in a neuronal cell line involves inhibition of cystine transport leading to oxidative stress. Neuron 1989;2:1547-58.

8. Bannai S. Exchange of cystine and glutamate across plasma membrane of human fibroblasts. J Biol Chem 1986;261:2256-63.

9. Murphy TH, Schnaar RL, Coyle JT. Immature cortical neurons are uniquely sensitive to glutamate toxicity by inhibition of cystine uptake. FASEB J 1990;4:1624-33.

10. Oka A, Belliveau MJ, Rosenberg PA, Volpe JJ. Vulnerability of oligodendroglia to glutamate: pharmacology, mechanisms and prevention. J Neurosci 1993;13:1441-53.

11. Davis JB, Maher P. Protein kinase $\mathrm{C}$ activation inhibits glutamateinduced cytotoxicity in a neuronal cell line. Brain Res 1994;652:169- 73.

12. Kato S, Higashida H, Higuchi Y, Hatakenaka S, Negishi K. Sensitive and insensitive states of cultured glioma cells to glutamate damage. Brain Res 1984;303:365-73.

13. Kato S, Negishi K, Mawatari K, Kuo CH. A mechanism for glutamate toxicity in the C6 glioma cells involving inhibition of cystine uptake leading to glutathione depletion. Neuroscience 1992;48:903-14.

14. Miyamoto M, Murphy TH, Schnaar RL, Coyle JT. Antioxidants protect against glutamate-induced cytotoxicity in a neuronal cell line. J Pharmacol Exp Ther 1989;250:1132-40.

15. Schubert D, Kimura H, Maher P. Growth factors and vitamin E modify neuronal glutamate toxicity. Proc Natl Acad Sci 1992;89:8264-7.

16. Tong G, Jahr CE. Block of glutamate transporters potentiates postsynaptic excitation. Neuron 1994;13:1195-203.

17. Diamond JS, Jahr CE. Transporters buffer synaptically released glutamate on a submillisecond time scale. J Neurosci 1997;17:4672-87.

18. Rothstein JD, Dykes-Hoberg M, Pardo CA, Bristol LA, Jin L, Kuncl RW, Kanai Y, Hediger MA, Wang Y, Schielke JP, Welty DF. Knockout of glutamate transporters reveals a major role for astroglial transport in excitotoxicity and clearance of glutamate. Neuron 1996;16:675-86.

19. Tanaka K, Watase K, Manabe T, Yamada K, Watanabe M, Takahashi K, Iwama H, Nishikawa T, Ichihara N, Kikuchi T, Okuyama S, Kawashima N, Hori S, Takimoto M, Wada K. Epilepsy and exacerbation of brain injury in mice lacking the glutamate transporter GLT-1. Science 1997;276:1699-702.

20. Gegelashvili G, Robinson MB, Trotti D, Rauen T. Regulation of glutamate transporters in health and disease. Prog Brain Res 2001;132:267-86. 
21. Choi DW. Glutamate receptors and the induction of excitotoxic neuronal death. Prog Brain Res 1994;100:47-51.

22. Maragakis NJ, Rothstein JD. Glutamate transporters in neurologic disease. Arch Neurol 2001;58:365-70.

23. Rossi DJ, Oshima T, Attwell D. Glutamate release in severe brain ischaemia is mainly by reversed uptake. Nature 2000;403:316-21.

24. Dutuit M, Touret M, Szymocha R, Nehlig A, Belin MF, DidierBazès $M$. Decreased expression of glutamate transporters in genetic absence epilepsy rats before seizure occurrence. J Neurochem 2002;80:1029-38.

25. Masliah E, Alford M, DeTeresa R, Mallory M, Hansen L. Deficient glutamate transport is associated with neurodegeneration in Alzheimer's disease. Ann Neurol 1996;40:759-66.

26. Plaitakis A, Shashidharan P. Glutamate transport and metabolism in dopaminergic neurons of substantia nigra: implications for the pathogenesis of Parkinson's disease. J Neurol 2000;247:S2:II2535.

27. Rothstein JD, Martin LJ, Kuncl RW. Decreased glutamate transport by the brain and spinal cord in amyotrophic lateral sclerosis. N Engl J Med 1992;326:1464-8.

28. Gilmore JL, Yi X, Quan L, Kabanov AV. Novel nanomaterials for clinical neuroscience. J Neuroimmune Pharmacol 2008;3:83-94.

29. Kabanov AV, Gendelman HE. Nanomedicine in the diagnosis and therapy of neurodegenerative disorders. Prog Polym Sci 2007;32: 1054-82.

30. Subramanian A, Krishnan UM, Sethuraman S. Development of biomaterial scaffold for nerve tissue engineering: Biomaterial mediated neural regeneration. J Biomed Sci 2009;16:108.

31. Ryu S, Kim BY. Culture of Neural Cells and Stem Cells on Graphene. J Tissue Eng Regen Med 2013;2:39-46.

32. Park S, Mohanty N, Suk JW, Nagaraja A, An J, Piner RD, Cai W, Dreyer DR, Berry V, Ruoff RS. Biocompatible, robust free-standing paper composed of a TWEEN/graphene composite. Adv Mater 2010;22:1736-40.

33. Agarwal S, Zhou X, Ye F, He Q, Chen GC, Soo J, Boey F, Zhang $\mathrm{H}$, Chen P. Interfacing live cells with nanocarbon substrates. Langmuir 2010;26:2244-7.

34. Lv M, Zhang Y, Liang L, Wei M, Hu W, Li X, Huang Q. Effect of graphene oxide on undifferentiated and retinoic acid-differentiated SH-SY5Y cells line. Nanoscale 2012;4:3861-6.

35. Lee WC, Lim CH, Shi H, Tang LA, Wang Y, Lim CT, Loh KP. Origin of enhanced stem cell growth and differentiation on graphene and graphene oxide. ACS Nano 2011;5:7334-41.

36. Paredes JI, Villar-Rodil S, Martínez-Alonso A, Tascón JM. Graphene oxide dispersions in organic solvents. Langmuir 2008;24:10560-4.

37. Rinaudo M. Chitin and chitosan: Properties and applications. Prog Polym Sci 2006;31:603-32.

38. Yang X, Tu Y, Li L, Shang S, Tao XM. Well-dispersed chitosan/graphene oxide nanocomposites. ACS Appl Mater Interfaces 2010;2:1707-13.

39. Zhang Y, Ali SF, Dervishi E, Xu Y, Li Z, Casciano D, Biris AS. Cytotoxicity effects of graphene and single-wall carbon nanotubes in neural phaeochromocytoma-derived PC12 cells. ACS Nano 2010;4:3181-6.

40. Croslan DR, Schoell MC, Ford GD, Pulliam JV, Gates A, Clement CM, Harris AE, Ford BD. Neuroprotective effects of neuregulin-1 on B35 neuronal cells following ischemia. Brain Res 2008; 1210:39-47.

41. Li N, Zhang X, Song Q, Su R, Zhang Q, Kong T, Liu L, Jin G, Tang M, Cheng G. The promotion of neurite sprouting and outgrowth of mouse hippocampal cells in culture by graphene substrates. Biomaterials 2011;32:9374-82.

42. Park SY, Park J, Sim SH, Sung MG, Kim KS, Hong BH, Hong S. Enhanced differentiation of human neural stem cells into neurons on graphene. Adv Mater 2011;23:H263-7

43. Weaver CL, Cui XT. Directed Neural Stem Cell Differentiation with a Functionalized Graphene Oxide Nanocomposite. Adv Healthc Mater 2015;4:1408-16.

44. Shah S, Yin PT, Uehara TM, Chueng ST, Yang L, Lee KB. Guiding stem cell differentiation into oligodendrocytes using graphene-nanofiber hybrid scaffolds. Adv Mater 2014;26:3673-80.

45. Wang Y, Lee WC, Manga KK, Ang PK, Lu J, Liu YP, Lim CT, Loh KP. Fluorinated graphene for promoting neuro-induction of stem cells. Adv Mater 2012; 24:4285-90.

46. Bae S, Kim H, Lee Y, Xu X, Park JS, Zheng Y, Balakrishnan J, Lei T, Kim HR, Song YI, Kim YJ, Kim KS, Ozyilmaz B, Ahn JH, Hong BH, Iijima S. Roll-to-roll production of 30-inch graphene films for transparent electrodes. Nat Nanotechnol 2010;5:574-8.

47. Depan D, Girase B, Shah JS, Misra RD. Structure-process-property relationship of the polar graphene oxide-mediated cellular response and stimulated growth of osteoblasts on hybrid chitosan network structure nanocomposite scaffolds. Acta Biomater 2011;7: 3432-45.

48. Zuo PP, Feng HF, Xu ZZ, Zhang LF, Zhang YL, Xia W, Zhang WQ. Fabrication of biocompatible and mechanically reinforced graphene oxide-chitosan nanocomposite films. Chem Cent J 2013; 7:39.

49. Pan Y, Wu T, Bao H, Li L. Green fabrication of chitosan films reinforced with parallel aligned graphene oxide. Carbohydrate Polymers 2011;83:1908-15.

50. Anderson CM, Swanson RA. Astrocyte glutamate transport: review of properties, regulation, and physiological functions. Glia 2000;32:1-14.

51. Greene LA, Tischler AS. Establishment of an or adrenergic clonal line of rat adrenal pheochromocytoma cells which respond to nerve growth factor Proc Natl Acad Sci 1976;73:2424-8.

52. Pereira CM, Oliveira CR. Glutamate toxicity on a PC12 cell line involves glutathione (GSH) depletion and oxidative stress. Free Radic Biol 1997;23:637-47.

53. Pereira CF, Oliveira CR. Oxidative glutamate toxicity involves mitochondrial dysfunction and perturbation of intracellular $\mathrm{Ca} 2+$ homeostasis. Neurosci Res 2000;37:227-66.

54. Penugonda S, Mare S, Lutz P, Banks WA, Ercal N. Potentiation of lead- induced cell death in PC12 cells by glutamate: protection by $\mathrm{N}$-acetylcysteineamide (NACA), a novel thiol antioxidant. Toxicol Appl Pharmacol 2006;216:197-205.

55. Pourzitaki C, Klagas I, Kaidoglou A, Tzimagiorgis G, Kritis A. Caspase dependent and independent cell death in naive and NGF treated PC12 cells after glutamate induced exitotoxicity. Epitheor Klin Farmakol Farmakokinet 2007;25:94-7.

56. Pourzitaki C, Kanellos G, Klagas I, Kritis A. Combined treatment of as partyl protease inhibitor and NMDA antagonist in Pc12 cells after glutamate excitotoxicity. Rev Clin Pharmacol Int Ed 2008;22: $304-7$. 
57. Pourzitaki C, Klagas I, Kanellos G, Kritis A. Calpaine mediated cell death in naive and NGF treated PC12 cells after glutamate induced exitotoxicity. Epitheor Klin Farmakol Farmakokinet 2009; 27:79-82.

58. Lu S, Lu C, Han Q, Li J, Du Z, Liao L, Zhao RC. Adipose-derived mesenchymal stem cells protect PC12 cells from glutamate excitotoxicity-induced apoptosis by upregulation of XIAP through PI3K/Akt activation. Toxicology 2010;279:189-95.

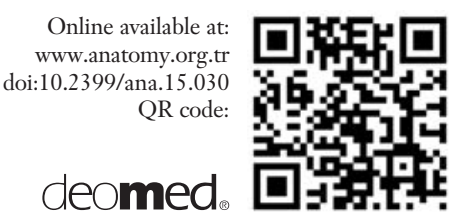

59. Bal-Price A, Brown GC. Nitric-oxide-induced necrosis and apoptosis in PC12 cells mediated by mitochondria. J Neurochem 2000; 75:1455-64.

60. Ma S, Liu H, Jiao H, Wang L, Chen L, Liang J, Zhao M, Zhang $\mathrm{X}$. Neuroprotective effect of ginkgolide $\mathrm{K}$ on glutamate-induced cytotoxicity in PC 12 cells via inhibition of ROS generation and Ca (2+) influx. Neurotoxicology 2011;33:59-69.

Correspondence to: Aylin Şendemir Ürkmez, PhD

Department of Bioengineering, Faculty of Engineering,

Ege University, 35100, Bornova, Izmir, Turkey

Phone: +90 5436073157

e-mail: sendemir@gmail.com

Conflict of interest statement: No conflicts declared.

This is an open access article distributed under the terms of the Creative Commons Attribution-NonCommercial-NoDerivs 3.0 Unported (CC BY-NCND3.0) Licence (http://creativecommons.org/licenses/by-nc-nd/3.0/) which permits unrestricted noncommercial use, distribution, and reproduction in any medium, provided the original work is properly cited. Please cite this article as: Kayhan B, Taşdemir Ş, Çoruk İlhan P, Görgün C, Şendemir Urkmez A, Şengül G. Graphene oxide has a neuroprotective effect against glutamate-induced excitoxicity on B35 neuroblastoma cell line. Anatomy 2015;9(3):156-167. 